04

\title{
Вольт-амперные характеристики высоковольтного искрового разряда по поверхности диэлектрика в вакууме
}

\author{
() В.И. Асюнин, С.Г. Давыдов, А.Н. Долгов, А.В. Корнеев, \\ А.А. Пшеничный, Р.Х. Якубов
}

Всероссийский научно-исследовательский институт автоматики им. Н.Л. Духова, Москва

E-mail: vniia4@vniia.ru

Поступило в Редакцию 13 декабря 2016 г.

Исследование временных зависимостей напряжения и тока высоковольтного искрового разряда по поверхности диэлектрика в вакууме обнаружило, что в присутствии продольного магнитного поля происходит затягивание переднего фронта импульса напряжения пробоя, а ток, в свою очередь, из четко выраженного импульса превращается в знакопеременные колебания. Наблюдалось замедление процесса пробоя при наличии предваряющего искру слаботочного разряда.

DOI: $10.21883 /$ PJTF.2017.07.44472.16599

Цель настоящей работы - изучить некоторые аспекты процесса перехода поверхности диэлектрика на границе с вакуумом в проводящее состояние при подаче на указанный промежуток импульса напряжения. Основной инструмент исследования - снятие временных зависимостей напряжения и тока разряда по поверхности диэлектрика. Интерес к поверхностному разряду связан с его применением в качестве источника плазмы для инициирования разряда в вакуумном промежутке сильноточного высоковольтного коммутатора [1].

Используемое в проведенных исследованиях электроразрядное устройство представляет собой трехэлектродную коаксиальную отпаянную систему (рис. 1). Основные элементы электроразрядной системы - анод; катод; поджигающий электрод; диэлектрическая шайба, разделяющая катод и поджигающий электрод и плотно зажатая между ними. Разрядное устройство размещается в герметичной диэлектрической оболочке, откачанной до давления $10^{-2}-10^{0} \mathrm{~Pa}$ и снабженной 


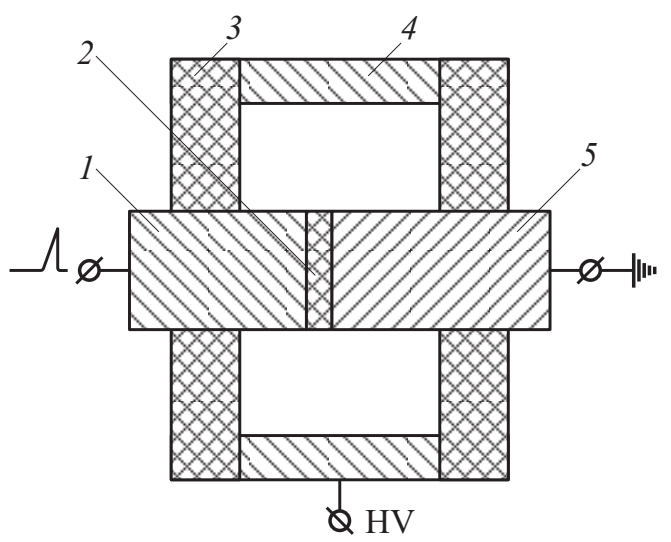

Рис. 1. Схема вакуумного электроразрядного устройства: 1 - поджигающий электрод; 2 - диэлектрическая шайба; 3 - герметичная диэлектрическая оболочка; 4 - анод; 5 - катод.

вакуумно-плотными выводами-тоководами, позволяющими подключать электроразрядное устройство к внешним цепям.

Диаметр катода составляет $5 \mathrm{~mm}$ при толщине диэлектрической шайбы $0.1 \mathrm{~m}$ либо $9 \mathrm{~mm}$ при толщине шайбы $1 \mathrm{~mm}$; зазор в промежутке катод-анод - 1 mm в обоих случаях. Материал электродов - алюминиевый сплав, материал диэлектрической шайбы - слюда. В описываемых экспериментах между диэлектрической шайбой и прилегающими электродами дополнительно и соосно с ними размещались металлические прокладки, каждая толщиной $0.1 \mathrm{~mm}$. Между диэлектрической шайбой и катодом - одна прокладка коваровая и вторая титановая, между диэлектрической шайбой и поджигающим электродом - единственная коваровая прокладка. Как показали ранее выполненные эксперименты, наличие указанных прокладок повышает стабильность срабатывания разрядного устройства.

Катод - заземлен. Анод до момента инициирования разряда находится под постоянным положительным либо отрицательным потенциалом до $3 \mathrm{kV}$ величиной. Для инициирования разряда на поджигающий электрод подается положительный относительно катода импульс напряжения амплитудой $3.5 \mathrm{kV}$ и крутизной $(1-2) \cdot 10^{9} \mathrm{~V} / \mathrm{s}$.

Письма в ЖТФ, 2017, том 43, вып. 7 
Измерения напряжения в разряде осуществлялись с помощью низкоиндуктивных омических и емкостных делителей; сила тока определялась исходя из напряжения на низкоиндуктивном сопротивлении, включенном в цепь разряда.

В ходе проведенных экспериментов не удалось зафиксировать влияние величины и знака начального потенциала анода, т. е. радиального электрического поля, на протекание тока по поверхности диэлектрика даже при максимальной толщине диэлектрической шайбы, сравнимой по протяженности с промежутком катод-анод. Вероятно, эффект влияния потенциала анода оказывается пренебрежимо малым по сравнению с эффектом усиления в тройной точке металл (поверхность катода) диэлектрик - вакуум в первую очередь того электрического поля, которое создается за счет разности потенциалов катода и поджигающего электрода.

Зафиксирована зависимость амплитуды тока поджига при минимальной продолжительности заднего фронта (на спаде) импульса напряжения поджига от толщины диэлектрической шайбы: с увеличением толщины шайбы амплитуда силы тока поджига снижается. При толщине диэлектрика $0.1 \mathrm{~mm}$ амплитуда силы тока поджига составила 7.5-10 A, при толщине диэлектрика $1 \mathrm{~mm}$ амплитуда силы тока поджига составила 3-4 А. Вероятно, высокая скорость образования и конечная скорость развития токового канала в поперечном направлении по отношению к направлению токового дрейфа частиц и в то же время высокая теплопроводность электропроводящей среды делают сопротивление токового канала зависящим главным образом от его пространственной протяженности.

Наблюдалась возможность затягивания до $\sim 100 \mathrm{~ns}$ процесса развития искрового разряда по поверхности диэлектрика толщиной $0.1 \mathrm{~mm}$ (рис. 2). В этом случае можно отметить прекращение и даже некоторое падение напряжения поджига примерно за $200 \mathrm{~ns}$ до момента, когда начинается развитие искрового разряда. Ток в цепи поджига при этом не регистрируется, т. е. надо полагать, что по поверхности диэлектрика или вблизи нее протекает слаботочный, скорее всего, тлеющий разряд. Наблюдаемая длительность импульса тока следующего затем искрового разряда составляет $100 \mathrm{~ns}$, и амплитуда снижена примерно до 2-3 А.

Можно предположить, что наличие проводящей среды - слабоионизованного остаточного газа, необходимой для протекания слаботочного разряда у границы металл (катод) - диэлектрик меняет картину 

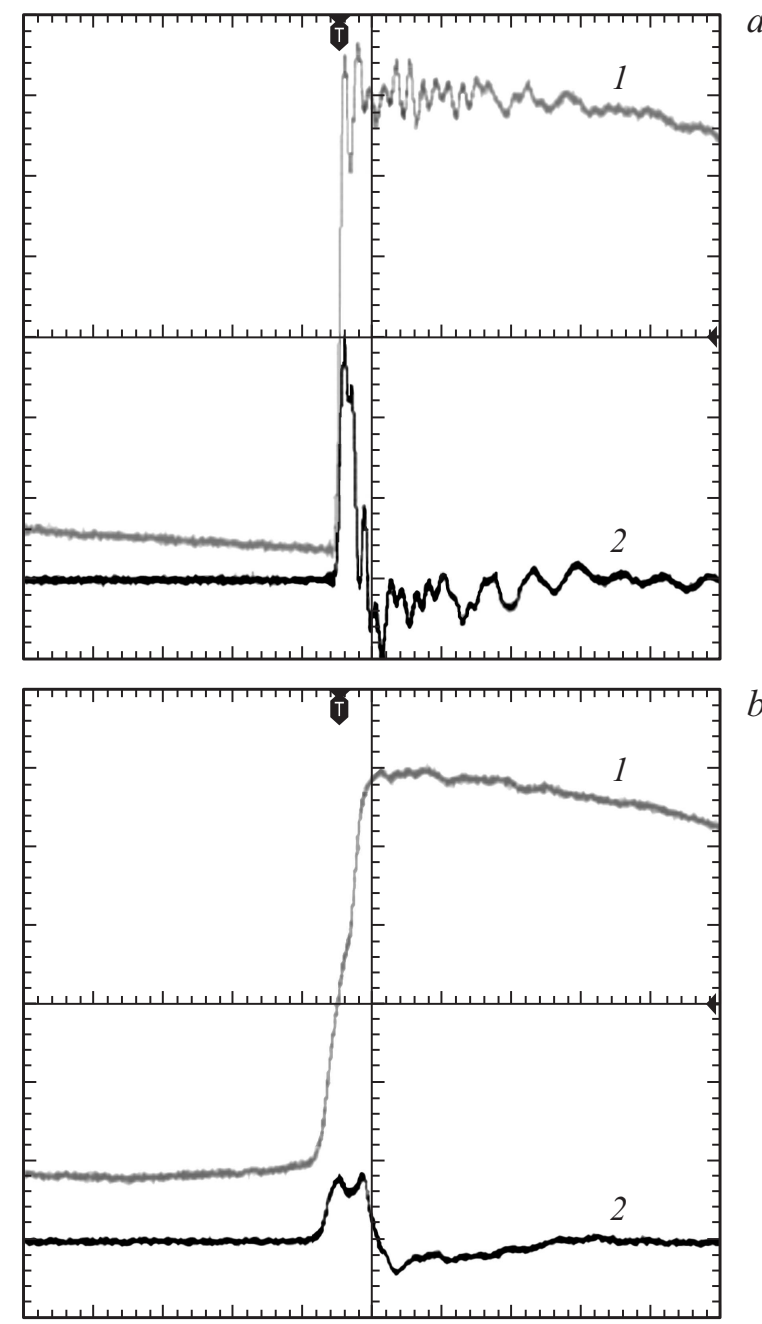

Рис. 2. Осциллограммы. $a-$ быстрый пробой, $b-$ медленный пробой. Развертка - $100 \mathrm{~ns} / \mathrm{grad}$; луч № 1 - напряжение поджига, чувствительность 500 V/grad; луч № 2 - ток поджига, чувствительность $2.5 \mathrm{~A} / \mathrm{grad}$.

6 Письма в ЖТФ, 2017, том 43, вып. 7 
электрического поля у поверхности металла, уменьшая среднюю напряженность электрического поля. С другой стороны, сделанное допущение - наличие плазмы у поверхности катода затрудняет формирование катодного пятна и искрового разряда - противоречит некоторым современным представлениям о механизмах генерации центров взрывной электронной эмиссии, связанным с накоплением электрических зарядов на диэлектрических пленках на поверхности металла в потоке редкой плазмы [2,3]. Впрочем, это может говорить и о том, что механизм формирования вторичных центров взрывной электронной эмиссии [4], связанный с взаимодействием плазменных струй и жидкометаллических капель в прикатодной области разряда, является более эффективным или более универсальным.

Удалось зафиксировать влияние внешнего коаксиального практически однородного магнитного поля с индукцией 0.05 Т на профиль осциллограмм напряжения и тока пробоя по поверхности диэлектрика при толщине диэлектрической шайбы $1 \mathrm{~mm}$ (рис. 3). Интерес к данному явлению вызван в связи с возможностью воздействовать магнитным полем на эрозионные процессы в вакуумном разряде, инициируемом пробоем по диэлектрику [1].

В присутствии магнитного поля, силовые линии которого были параллельны поверхности диэлектрика и сонаправлены силовым линиям электрического поля, происходит затягивание переднего фронта импульса напряжения пробоя с $\sim 10$ до $\sim 60-100 \mathrm{~ns}$. Ток поджига, т.е. ток в промежутке катод - поджигающий электрод, в свою очередь, из четко выраженного импульса длительностью примерно $30 \mathrm{~ns}$ и амплитудой 3-4А превращается в знакопеременные колебания с нарастающей до $\sim 1 \mathrm{~A} \mathrm{в} \mathrm{течение} \sim 150 \mathrm{~ns}$ амплитудой. При толщине шайбы $0.1 \mathrm{~mm}$ влияние указанного магнитного поля не обнаружено даже при индукции поля $0.15 \mathrm{~T}$.

Можно предположить, что присутствие у поверхности диэлектрика вмороженной в магнитное поле электронной компоненты плазмы приводит к раскачке в ней альфвеновских волн при выбросах плазмы из центров взрывной электронной эмиссии. Поперечные по отношению к поверхности диэлектрика и линиям индукции колебания электронной компоненты, по-видимому, и приводят к искажению регистрируемой формы импульса тока поджига. Период наблюдаемых, вероятно, альфвеновских по своей природе колебаний составляет $40 \mathrm{~ns}$. На основе данных спектрометрических исследований экспериментально установ- 


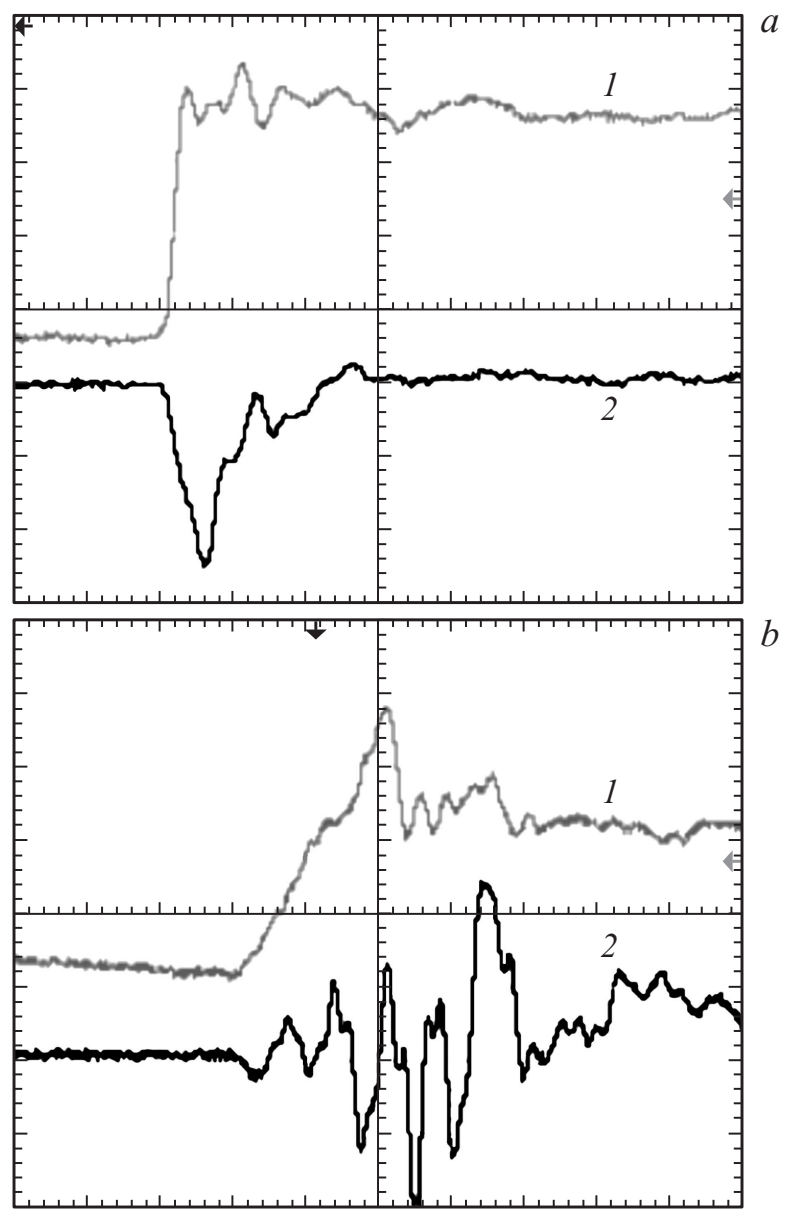

Рис. 3. Осциллограммы. $a$ - магнитное поле отсутствует: развертка $25 \mathrm{~ns} / \mathrm{grad}$; луч № 1 - напряжение поджига, чувствительность $500 \mathrm{~V} / \mathrm{grad}$; луч № 2 ток поджига, чувствительность $2 \mathrm{~A} / \mathrm{grad} . b-$ однородное продольное магнитное поле: индукция $0.05 \mathrm{~T}$; развертка $50 \mathrm{~ns} / \mathrm{grad}$; луч № 1 - напряжение поджига, чувствительность $500 \mathrm{~V} / \mathrm{grad}$; луч № 2 - ток поджига, чувствительность $0.5 \mathrm{~A} / \mathrm{grad}$.

$6^{*}$ Письма в ЖТФ, 2017, том 43, вып. 7 
лен тот факт, что плазма, испускаемая на ранней стадии существования катодного пятна, т. е. на стадии искры, является слабоионизованной (не более $1 \%$ ) с концентрацией заряженных частиц на уровне $10^{24} \mathrm{~m}^{-3}[5,6]$. Если размер центра взрывной электронной эмиссии принять порядка $1 \mu \mathrm{m}$ [3], а плотность испускаемой им плазмы считать убывающей обратно пропорционально квадрату расстояния [7], то на расстоянии $\sim 100 \mu \mathrm{m}$ от центра взрывной электронной эмиссии концентрация заряженных частиц составит $\sim 10^{20} \mathrm{~m}^{-3}$. Для концентрации заряженных частиц $\sim 10^{20} \mathrm{~m}^{-3}$ исходя из величины скорости альфвеновских волн

$$
v_{A}=B /\left(\mu_{0} M n\right)^{1 / 2}
$$

и соотношения

$$
v_{A}=\lambda / T
$$

где $v_{A}-$ скорость альфвеновских волн, $B-$ индукция магнитного поля, $\lambda$ - длина волны, $T$ - период колебаний, $\mu_{0}$ - магнитная постоянная, $M$ - масса иона, получим в качестве оценки длины волны вблизи катода (а при толщине диэлектрика $0.1 \mathrm{~mm}$ и вблизи поджигающего электрода) величину $\sim 1 \mathrm{~mm}$. При толщине диэлектрика $1 \mathrm{~mm}$ оценка даст $\sim 1 \mathrm{~cm}$ для длины волны вблизи поджигающего электрода. При проведении оценки мы полагали, что электронная компонента плазмы будет вовлекать в колебательное движение и ионную компоненту.

Остается добавить, что, по-видимому, при толщине диэлектрика $1 \mathrm{~mm}$ влияние рассмотренных колебаний на протекающий у поверхности диэлектрика ток достаточно сильно различается вблизи катода и поджигающего электрода, и поэтому оказывается заметным, например, в результате действия более сильного электрического поля за счет разделения зарядов и большей концентрации нескомпенсированного заряда частиц вблизи катода. Колебания линий индукции магнитного поля, вдоль которых движутся по спиральным траекториям электроны, также оказывают воздействие на процесс переноса электронов от катода к поджигающему электроду, либо прижимая электроны к поверхности диэлектрика, где они испытывают более частые столкновения с тяжелыми частицами, либо отталкивая их от поверхности в область меньшей концентрации тяжелых частиц.

При наличии магнитного поля падает амплитуда тока поджига, текущего по поверхности диэлектрика толщиной $1 \mathrm{~mm}$, следовательно, падает мощность в канале тока, замедляется процесс ионизации 
газообразных продуктов эрозии и рост проводимости канала тока, затягивается передний фронт импульса напряжения пробоя.

Таким образом, во-первых, получено косвенное свидетельство в пользу механизма формирования вторичных центров взрывной электронной эмиссии в результате взаимодействия плазменных струй и жидкометаллических капель в прикатодной области искрового разряда. Во-вторых, обнаружено, что наличие магнитного поля, силовые линии которого параллельны поверхности диэлектрика и сонаправлены силовым линиям электрического поля, может оказать существенное влияние на условия протекания тока пробоя по поверхности диэлектрика, вероятно, в результате раскачки альфвеновских волн.

\section{Список литературы}

[1] Асюнин В.И., Давыдов С.Г., Долгов А.Н. и др. // Вопросы атомной науки и техники. Сер. Термоядерный синтез. 2015. Т. 38. В. 3. С. 49-52.

[2] Иванов В.А., Сахаров А.С., Коныжеев М.E. // Успехи прикладной физики. 2013. T. 1. № 6. C. 697-711.

[3] Иванов В.A., Сахаров А.С. // 21-я Всероссийская (с международным участием) конференция „Физика низкотемпературной плазмы“ ФНТП-2014. Казань, 20-23 мая 2014. Казань: Изд-во КНИТУ, 2014. Т. 2. С. 14-17.

[4] Баренгольи, С.А., Месяи Г.А. // Физика экстремальных состояний вещества / Под ред. В.Е. Фортова, В.П. Ефремова, К.В. Хищенко и др. Черноголовка: Институт проблем химической физики РАН, 2002. С. 128-129.

[5] Galburt V.A., Zelenin A.E., Sikharulidze G.G. // Int. J. Mass Spectr. Ion Process. 1984. V. 55. N 2. P. $125-132$.

[6] Methling R., Popov S.A., Batrakov A.V. et al. // IEEE Trans. Plasma Sci. 2013. V. 41. Iss. 8/2. P. 1904-1910.

[7] Jüttner B., Förster A. // Proc. XVII Int. Symposium on Discharges and Electrical Insulation in Vacuum. Berkeley, 1996. P. 118.

Письма в ЖТФ, 2017, том 43, вып. 7 